www.jmscr.igmpublication.org Impact Factor 5.244

Index Copernicus Value: 83.27 ISSN (e)-2347-176x ISSN (p) 2455-0450

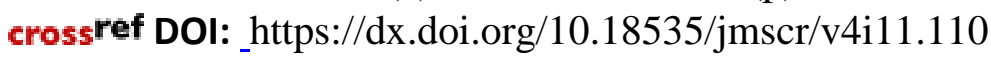

Journal Of Medical Science And Clinical Research

\title{
Prevalence and Associated Factors of Pressure Ulcer among Hospitalized Adults at Debre Markos Referral Hospital, East Gojjam Zone, Ethiopia, 2016: Cross-Sectional study
}

Authors

\section{Benalfew Lake Mengisitie (MSc.AHN RN) ${ }^{1}$, Ato Balcha Berhanu (MSc, BSc, RN) ${ }^{2}$, Ato Dessalegn Haile (MSc,AHN,RN) ${ }^{3}$, Ato Bekele Tesfaye (MSc, AHN RN) ${ }^{4}$}

${ }^{1}$ Dept of Nursing, Medicine and Health Science College, Debre Markos University, Debre Markos, Ethiopia Email: benalfew@gmail.com

${ }^{2}$ Addis Ababa University College of Health Sciences, School of Allied Health Sciences, Department of Nursing and Midwifery

Email:mr.hearta@yahoo.com

${ }^{3}$ Dept of Nursing, Medicine and Health Science College, Debre Markos University, Debre Markos, Ethiopia e.mail: dessalegnhaile@gmail.com.

${ }^{4}$ Dept of Nursing, Medicine and Health Science College, Debre Markos University, Debre Markos, Ethiopia Email: bekeletesfaye76@gmail.com

\begin{abstract}
Introduction: Pressure ulcers (PUs) occur frequently in hospitalized, community-dwelling and nursing home older adults, and serious problems that can lead to sepsis or death. Pressure ulcers are additional co-morbid threat / conditions encountered in hospitalized patients or those requiring long-term institutional care.

Objective: To assess prevalence and associated factors of pressure ulcer among hospitalized adults at Debre Markos referral hospital, East Gojjam Zone, Ethiopia, 2016.

Method: Institution-based, cross-sectional quantitative study design was conducted on a representative sample of 236 hospitalized adults in the study area from February 15/2016 to April 15/2016. Statistical software, Epi data version 3.1 and SPSS version 23 were used. Univariate, Bivariate and Multivariate logistic regression models were used identifying the association; degree of association was interpreted by using ORs with 95\% confidence intervals and $P$-value $\leq 0.05$ was considered statistically significant with the outcome variable.

Result: A total of 8 pressure ulcer was detected from 236 patients, with the prevalence rate of 3.4\%. Majority of respondents $3.0 \%$ developed pressure ulcer came from the rural area and $1.3 \%$ (3) patients developed ulcer was not educated.

Participants who had constantly moist skin were 3.2 times [95\% CI: AOR, 3.202[2.050 -16.067] more risk to develop pressure ulcer than rarely moist skin in moisture, and participants who had been very poor in nutrition were 4.9 times [95\% CI: AOR, 4.9(3.837 - 23.326)] at higher risk to develop pressure ulcer than adequate in nutrition.

Conclusion and Recommendation: The prevalence of pressure ulcer was slightly high among hospitalized adult patients. They developed pressure ulcer at factors such as bed ridden, moist skin, inadequate in nutrition and who had not got frequent position change service. Therefore, frequent position change service and Braden scale PU risk assessment tool should be applied to prevent \& reduce the prevalence of pressure ulcer.

Keywords: Pressure ulcer, prevalence \& Associated factors.
\end{abstract}




\section{Background}

A pressure ulcer (PU) (also known as pressure sore, pressure injury (PI), decubitus ulcer or bed sore),has previously been defined as "an area of localized damage to the skin and underlying tissue caused by pressure, shear and or a combination of these ${ }^{(1-4)}$. PU leads to ischemia, cell death \& tissue necrosis, as capillaries are compressed and the blood flow is restricted, the cutaneous tissues become broken or destroyed, leading to progressive destruction and necrosis of underlying soft tissues. This process results in a painful and slow healing of pressure ulcer ${ }^{(5)}$. The formation of a new pressure ulcer while hospitalized has been defined by the National Quality Forum (NQF) as a hospital-acquired condition (HAC) that is high-cost and high-volume and may be preventable with implementation of evidencebased guidelines ${ }^{(6)}$. Pressure ulcers remain a significant problem in hospitals as well as domestic and community settings. They have been described by both the National Pressure Ulcer
Advisory Panel (NPUAP) and the European Pressure Ulcer Advisory Panel (EPUAP) as 'localized injury to the skin and/or underlying tissue usually over a bony prominence as a result of pressure combined with shear and it has long been recognized as a major cause of morbidity, mortality and health care burden globally ${ }^{(7)}$.

Development of pressure ulcers is complex and multi-factorial. In critical care patients, pressure ulcers are an additional co-morbid threat in patients who are already physiologically compromised. In fact, pressure ulcers are one of the most underrated medical problems in critical care patients. Despite advances in medical technology and the use of formalized prevention programs based on clinical practice guidelines, the prevalence of pressure ulcers during hospitalization continues to increase ${ }^{(8)}$. Therefore, enormous effort is required to find effective and reliable techniques for preventing the initiation of ulcers and eliminating them once they develop ${ }^{(9)}$.

\subsection{Conceptual Framework}

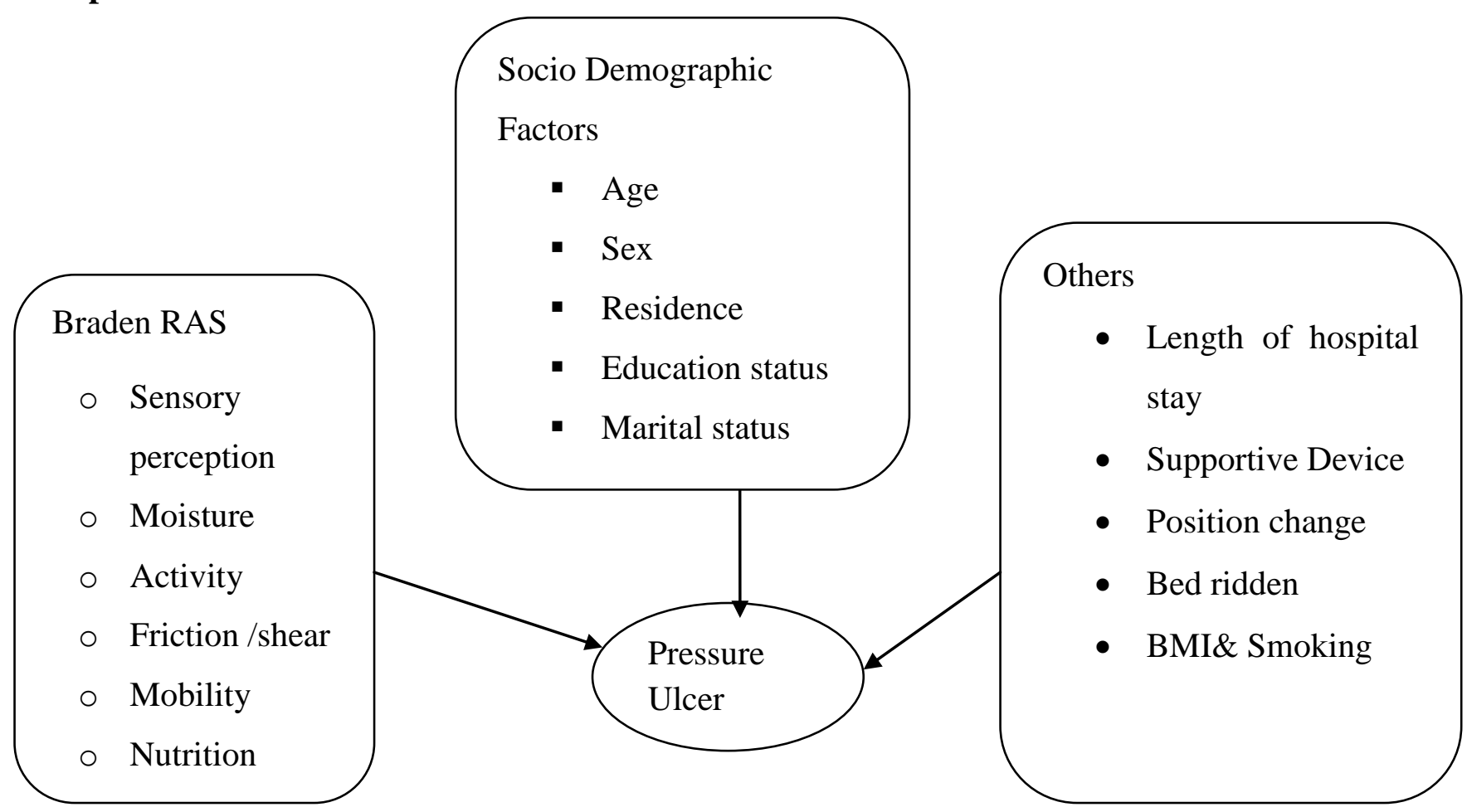

Figure 1: Diagrammatic representation of a conceptual framework, newly developed had shown the relationship between the outcome variable and independent variables.

Source: Supported by different literatures ${ }^{(5,8,10,16,20-23,25)}$. 


\section{Objectives}

\subsection{General objective}

To assess prevalence and associated factors of pressure ulcer among hospitalized adults at Debre Markos referral hospital, East Gojjam Zone, 2016.

\subsection{Specific objectives}

To describe prevalence of pressure ulcer among hospitalized adults at Debre Markos referral hospital.

To identify associated factors of pressure ulcer among hospitalized adults at Debre Markos referral hospital.

\section{Method}

Institution- based, cross-sectional quantitative study design was conducted, and the study period was from February 15 to April 15, 2016. The study was conducted at Debre Markos referral hospital, East Gojjam Zone. This Zone is found in the Amhara region that comprises eleven Woredas and 2,152,671 populations (26). Debre Markos is a zonal town which is found $300 \mathrm{~km} \&$ 260km away from Addis Ababa and Bahir Dar respectively.

Debre Markos Referral Hospital is one of the referral hospitals in the Amhara region in Ethiopia and it is expected to give service for about three million people for the nearby zone \& woredas' people and it has different wards. In the study wards, 42 beds are in Medical, 30 in Surgical and 28 in Gyn.Obs. In the hospital, previous study had not been conducted on the issue of prevalence and associated factors of pressure ulcer among hospitalized adults.

\subsection{Operational Definition}

Braden RAS/ Braden scale scores: In this study, Patients were vulnerable to pressure ulcer development when Braden score $<17$ or with a pressure ulcer and no risk of pressure ulcer at Braden score $\geq 17^{(3)}$.

\subsection{Data Collection Procedures and Quality Control}

Data concerning prevalence and determining factors of PU were collected through interview and physical examination techniques. The Braden scale risk assessment tool was used to assess the risk of PU and comprised the following items: sensory perception, skin moisture, physical activity, mobility, nutrition, and friction/shear. The Braden Scale is a summated rating scale made up of six subscales scored from 1-3 or 4, for total scores that range from 6-22. A lower Braden Scale Score indicates a lower level of functioning and, therefore, a higher level of risk for pressure ulcer development ${ }^{(27)}$. The standardized questionnaire's tool had been prepared in English language and translated into local/Amharic language /in order to standardize the way questions would be asked. After translating it, retranslation back into the original language had been done by language expert.

Two Bsc nurses\& one Bsc midwife nurse for data collection and three Health Officers for supervision would be selected from Debre Markos University. Training was given by the principal investigator for data collectors and supervisors. During data collection, the data collectors filled the data from each patient based on the checklists. Inspection for completeness and quality of data had been carried out by principal investigator.

\subsection{Data Entry and Analysis}

The questionnaires that would be filled by the data collectors were going to be checked its completeness and then cleaned, coded \& entered into Epi data version 3.1statistical software and then exported to SPSS version $23 \&$ analyzed. Univariate for descriptive statistics and both bivariate \& multivariate logistic regression models for association were used ; degree of association was interpreted by using ORs with $95 \%$ confidence intervals and P-value $\leq 0.05$ was considered statistically significant with the outcome variable.

\subsection{Ethical consideration}

Ethical clearance was obtained and a formal letter of cooperation had been written to Debre Markos referral hospital from Addis Ababa University College of Health Sciences, School of Allied Health Sciences, and Department of Nursing And 
Midwifery Ethical Review Board. The purposes and the importance of the study had been explained \& oral consent was obtained from each study participants. Information was given that study participants have full right not to participate in the study if they were not willing. To ensure confidentiality, anonymity was explained clearly to the participants. Nursing care was given for those patients who developed pressure ulcer during study period.

\section{Result}

\subsection{Socio-Demographic Characteristics}

A total of 236 admitted patients at Debre Markos referral hospital were included in this study with the response rate of $100 \%$. Majority of, $82.2 \%$ (194) and 59.7\% (141) respondents were rural residents and males in sex respectively, and the respondents $76.7 \%$ (81) were married. In addition, $25.4 \%$ (60) of the respondents were not educated (Table-1).

Table 1: Socio-demographic Characteristics of the respondents who were admitted at Debre Markos referral hospital, East Gojjam, Ethiopia, $2016(\mathrm{~N}=236)$.

\begin{tabular}{|l|ll|}
\hline \multicolumn{1}{|c|}{ Variables } & Frequency(n) & Percent (\%) \\
\hline Age & 108 & 45.8 \\
$\mathbf{1 8 - 3 2}$ & 76 & 32.2 \\
$\mathbf{3 3 - 5 3}$ & 52 & 22.0 \\
$\mathbf{2 5 4}$ & & \\
\hline Sex & 95 & 40.3 \\
Female & 141 & 59.7 \\
Male & & \\
\hline Place of residence & 42 & 17.8 \\
Urban & 194 & 82.2 \\
Rural & & \\
\hline Marital status & & \\
Single & 32 & 13.6 \\
Married & 81 & 76.7 \\
Divorced & 11 & 4.7 \\
Widowed & 12 & 5.1 \\
\hline Educational level & & \\
Unable to read \& write & & 25.4 \\
Read \& Write & 60 & 17.4 \\
Grade 1-4 & 41 & 8.5 \\
Grade 5-6 & 20 & 20.8 \\
Grade 7-8 & 49 & 15.7 \\
Grade 9-10 & & \\
Grade 11 and above & 37 & \\
\hline
\end{tabular}

The study participants were found in the age range of 18 - 32 (45.8\%) and the median age of the respondents were 35 years with the mean of 38.97 , standard deviation of 16.141 and shown a parametric or normal distribution (Fig.3). 


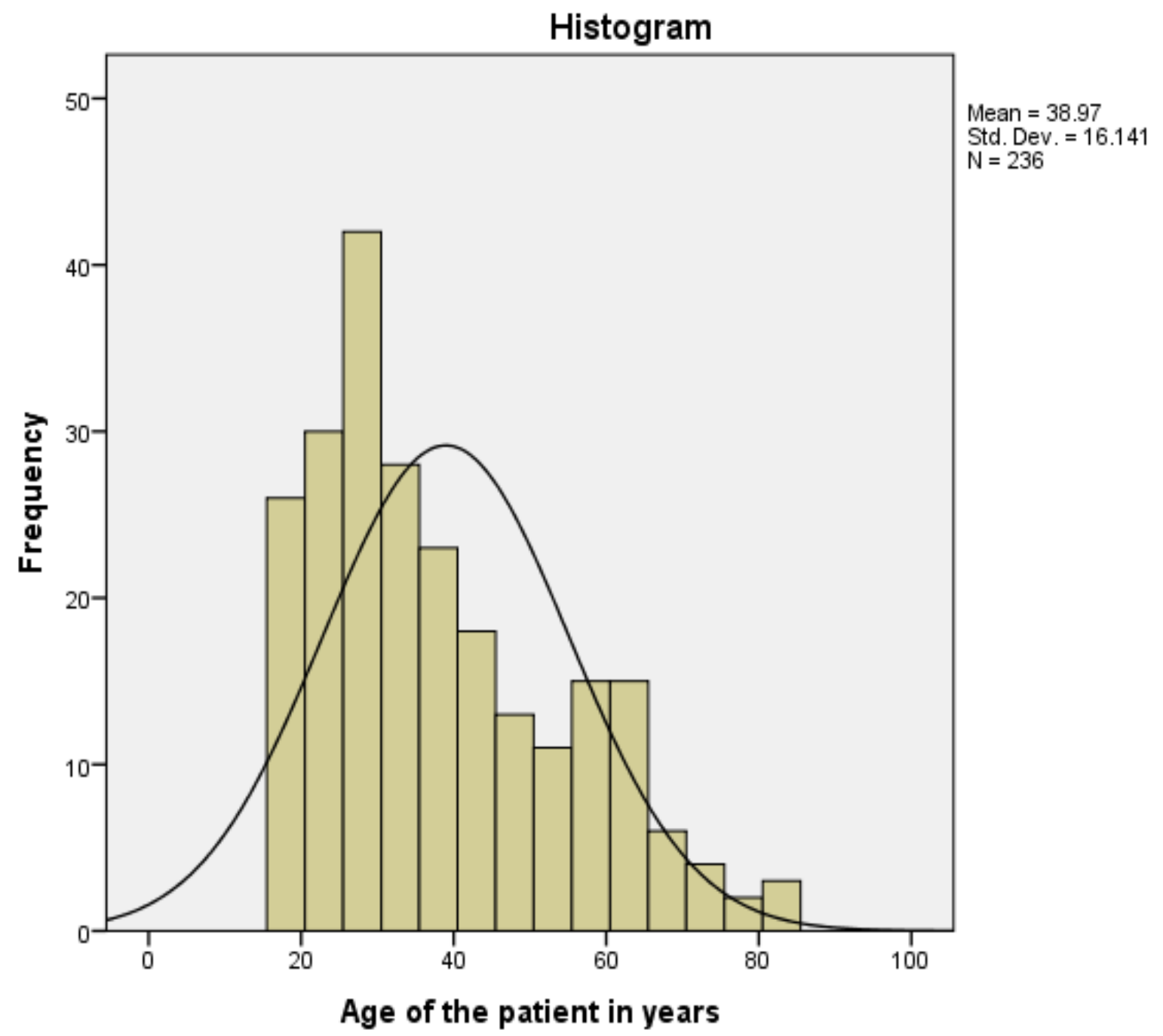

Figure 2: Age distribution of the participants in years who were admitted at Debre Markos Referral hospital, East Gojjam, 2016. 


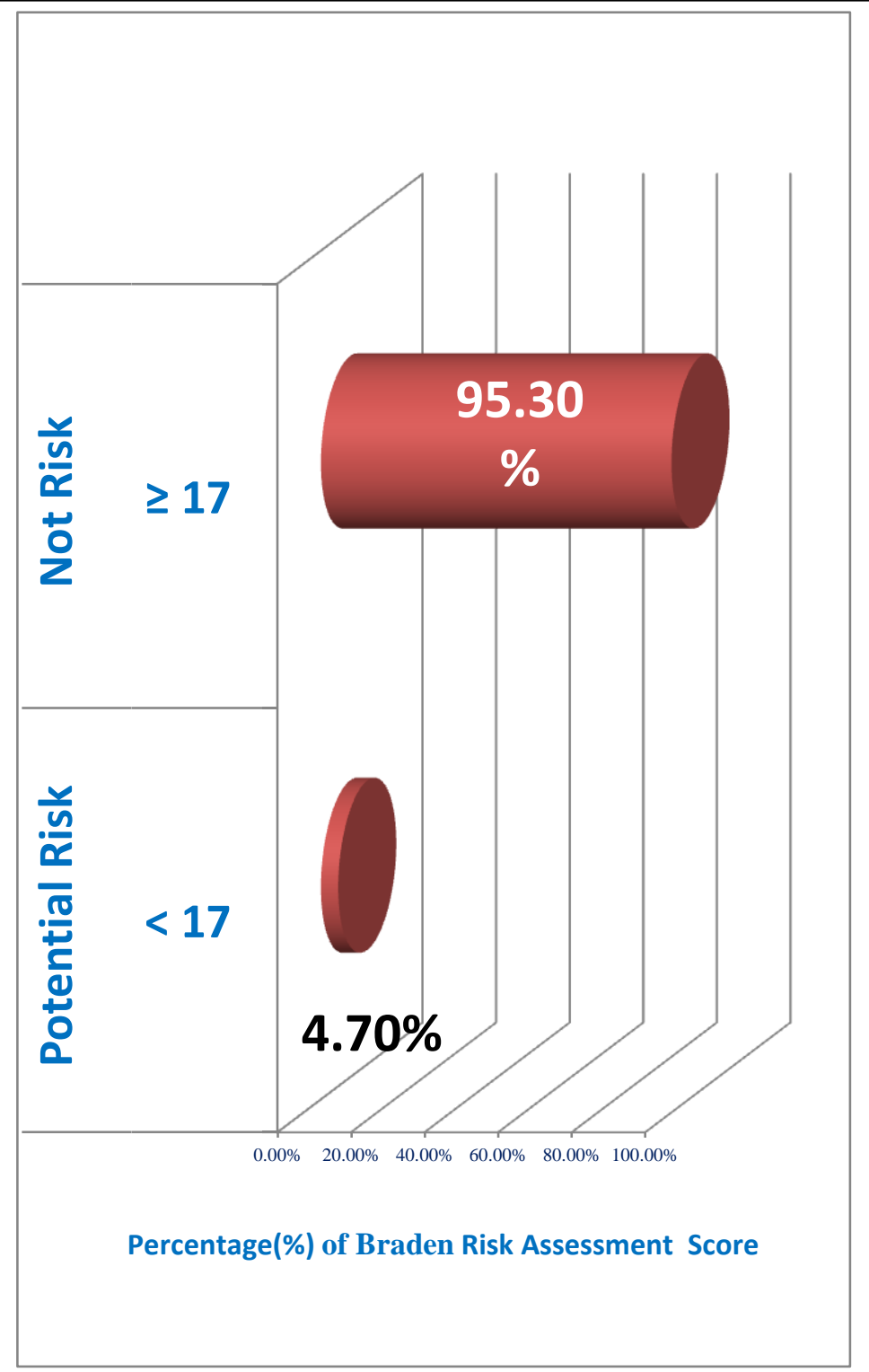

Braden Risk Assessment Scale Score.

Of the respondents $4.7 \%$ ( 11) were potentially at risk to develop pressure ulcer and $95.30 \%$ (225) were not at risk in developing pressure ulcer (Fig.4).

Figure 3: Braden scale risk assessment score of the patient who were admitted at Debre Markos Referral hospital, East Gojjam, 2016.

\subsection{Prevalence of pressure ulcer}

\subsubsection{Prevalence of pressure ulcer with socio-} demographic variables

A total of 8 pressure ulcer was detected from 236 patients, with the prevalence rate of $3.4 \%$. Majority of respondents $3.0 \%$ developed pressure ulcer came from the rural area, and $1.3 \%$ (3) patients developed ulcer were not educated (Table 2). 
Table 2: Descriptive statistics of socio-demographic variables in pressure ulcer development who were admitted at Debre Markos Referral Hospital, East Gojjam, Ethiopia, 2016 ( $n=236$ ).

\begin{tabular}{|c|c|c|c|c|}
\hline Over all pressure Ulcer & 8 & 3.4 & 228 & 96.6 \\
\hline $\begin{array}{l}\text { Age } \\
18-32 \\
33-53 \\
\geq 54\end{array}$ & $\begin{array}{l}1 \\
2 \\
5\end{array}$ & $\begin{array}{l}.4 \\
.8 \\
2.1\end{array}$ & $\begin{array}{l}107 \\
74 \\
47\end{array}$ & $\begin{array}{l}45.3 \\
31.4 \\
19.9\end{array}$ \\
\hline $\begin{array}{l}\text { Sex } \\
\text { Female } \\
\text { Male }\end{array}$ & $\begin{array}{l}2 \\
6\end{array}$ & $\begin{array}{l}.8 \\
2.5\end{array}$ & $\begin{array}{l}93 \\
135\end{array}$ & $\begin{array}{l}39.4 \\
57.2\end{array}$ \\
\hline $\begin{array}{l}\text { Place of residence } \\
\text { Urban } \\
\text { Rural }\end{array}$ & $\begin{array}{l}1 \\
7\end{array}$ & $\begin{array}{l}.4 \\
3.0\end{array}$ & $\begin{array}{l}41 \\
187\end{array}$ & $\begin{array}{l}17.4 \\
79.2\end{array}$ \\
\hline $\begin{array}{l}\text { Marital status } \\
\text { Single } \\
\text { Married } \\
\text { Divorced } \\
\text { widowed }\end{array}$ & $\begin{array}{l}1 \\
5 \\
1 \\
1\end{array}$ & $\begin{array}{l}.4 \\
2.1 \\
.4 \\
.4\end{array}$ & $\begin{array}{l}31 \\
176 \\
10 \\
11\end{array}$ & $\begin{array}{l}13.1 \\
74.6 \\
4.2 \\
4.7\end{array}$ \\
\hline $\begin{array}{l}\text { Educational status } \\
\text { Not educated } \\
\text { Read and write } \\
\text { Grade } 1-4 \\
\text { Grade 5-8 } \\
\text { Grade } 9-10 \\
\geq \text { grade } 11\end{array}$ & $\begin{array}{l}3 \\
1 \\
1 \\
1 \\
1 \\
1\end{array}$ & $\begin{array}{l}1.3 \\
.4 \\
.4 \\
.4 \\
.4 \\
.4\end{array}$ & $\begin{array}{l}57 \\
40 \\
19 \\
48 \\
36 \\
28\end{array}$ & $\begin{array}{l}24.2 \\
16.9 \\
8.1 \\
20.3 \\
15.3 \\
11.9\end{array}$ \\
\hline
\end{tabular}

\subsubsection{Prevalence of pressure ulcer with other} variables.

Almost half $48.3 \%$ (114) admitted patients at Debre Markos referral hospital had $8-15$ days length of stay in the hospital and $38.5 \%$ (91) patients discharged less than or equal to 7 days, whereas $13.1 \%$ (31) patients stay in hospital more than 16 days. $1.7 \%(4)$ of respondents who developed pressure ulcer were admitted $\geq 16$ days. From the total participants who developed pressure ulcer, $0.8 \%$ (2) had not used pressure relieving device, $2.1 \%$ (5) with a body mass index of 18.5-24.9 and 1.7\% (4) had not been changed their position frequently by nurses (Table $3)$. 
Table 3: Descriptive statistics of other variables in pressure ulcer development who were admitted at Debre Markos Referral Hospital, East Gojjam, Ethiopia, 2016 ( $\mathrm{n}=236)$.

\begin{tabular}{|c|c|c|c|c|}
\hline & \multicolumn{4}{|c|}{ Pressure Ulcer } \\
\hline Variables & \multicolumn{2}{|l|}{ Yes } & \multicolumn{2}{|c|}{ No } \\
\hline & $\mathbf{N}$ & $\%$ & n & $\%$ \\
\hline \multicolumn{5}{|l|}{ BMI } \\
\hline$<18.5$ & 1 & .4 & 9 & 3.8 \\
\hline 18.5-24.9 & 5 & 2.1 & 206 & 87.3 \\
\hline 25.0-29.9 & 1 & .4 & 11 & 4.7 \\
\hline$>=30$ & 1 & .4 & 2 & .8 \\
\hline \multicolumn{5}{|l|}{ Smoking } \\
\hline Currently smoking & 1 & .4 & 0 & 0 \\
\hline Previous smoking & 1 & .4 & 4 & 1.7 \\
\hline No smoking & 6 & 2.5 & 224 & 94.9 \\
\hline \multicolumn{5}{|l|}{ Length of stay } \\
\hline$\leq 7$ days & 1 & .4 & 90 & 38.1 \\
\hline 8 -15 days & 3 & 1.3 & 111 & 47.0 \\
\hline$>16$ davs & 4 & 1.7 & 27 & 11.4 \\
\hline \multicolumn{5}{|l|}{ Bed ridden } \\
\hline Yes & 3 & 1.3 & 2 & .8 \\
\hline No & 5 & 2.5 & 226 & 95.8 \\
\hline \multicolumn{5}{|l|}{ Change of position } \\
\hline Yes & 4 & 1.7 & 227 & 96.2 \\
\hline No & 4 & 1.7 & 1 & .4 \\
\hline \multicolumn{5}{|l|}{ Supportive device } \\
\hline Yes & 6 & 2.5 & 223 & 94.5 \\
\hline No & 2 & .8 & 5 & 2.5 \\
\hline
\end{tabular}

\subsubsection{Prevalence of pressure ulcer with wards}

The prevalence of pressure ulcer in terms of wards was identified, surgical ward ulcer prevalence was

$2.1 \%$ (5) (Fig.5).

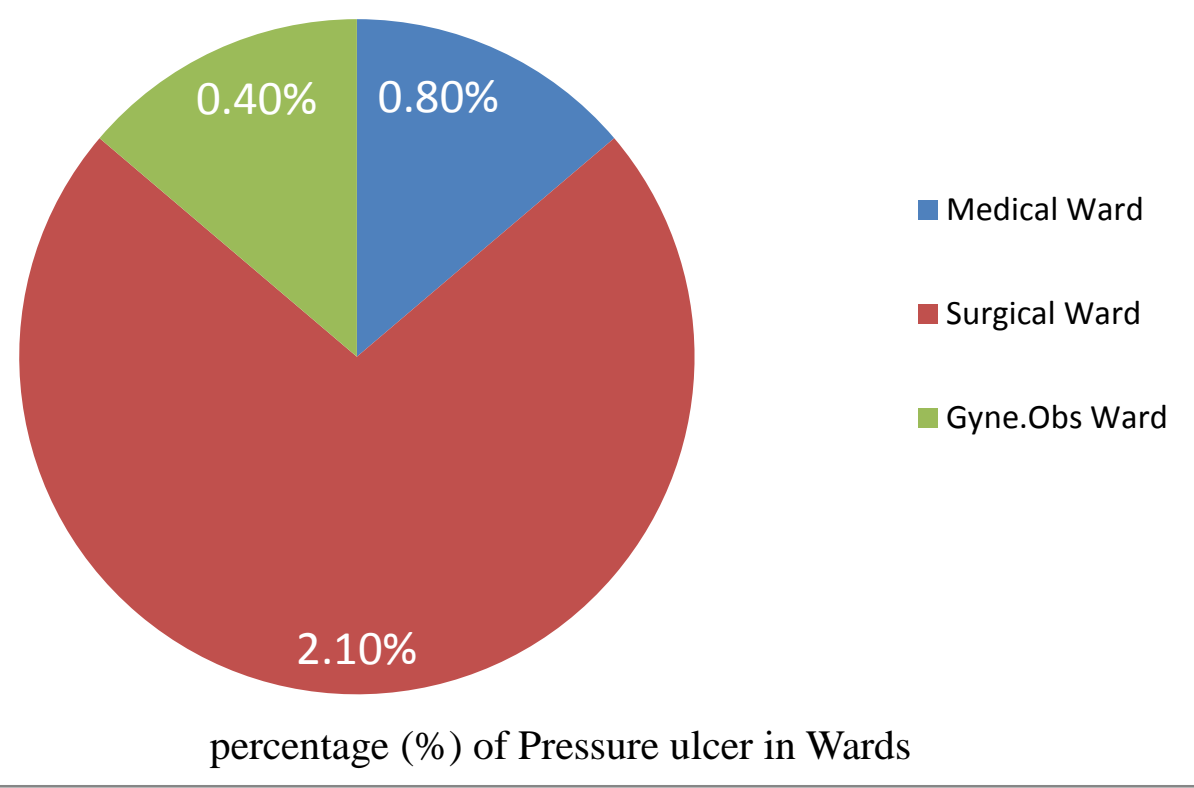

Figure 4: Pressure Ulcer with Wards of the respondents who were admitted at Debre Markos Referral Hospital, East Gojjam, Ethiopia, 2016 (n=236). 


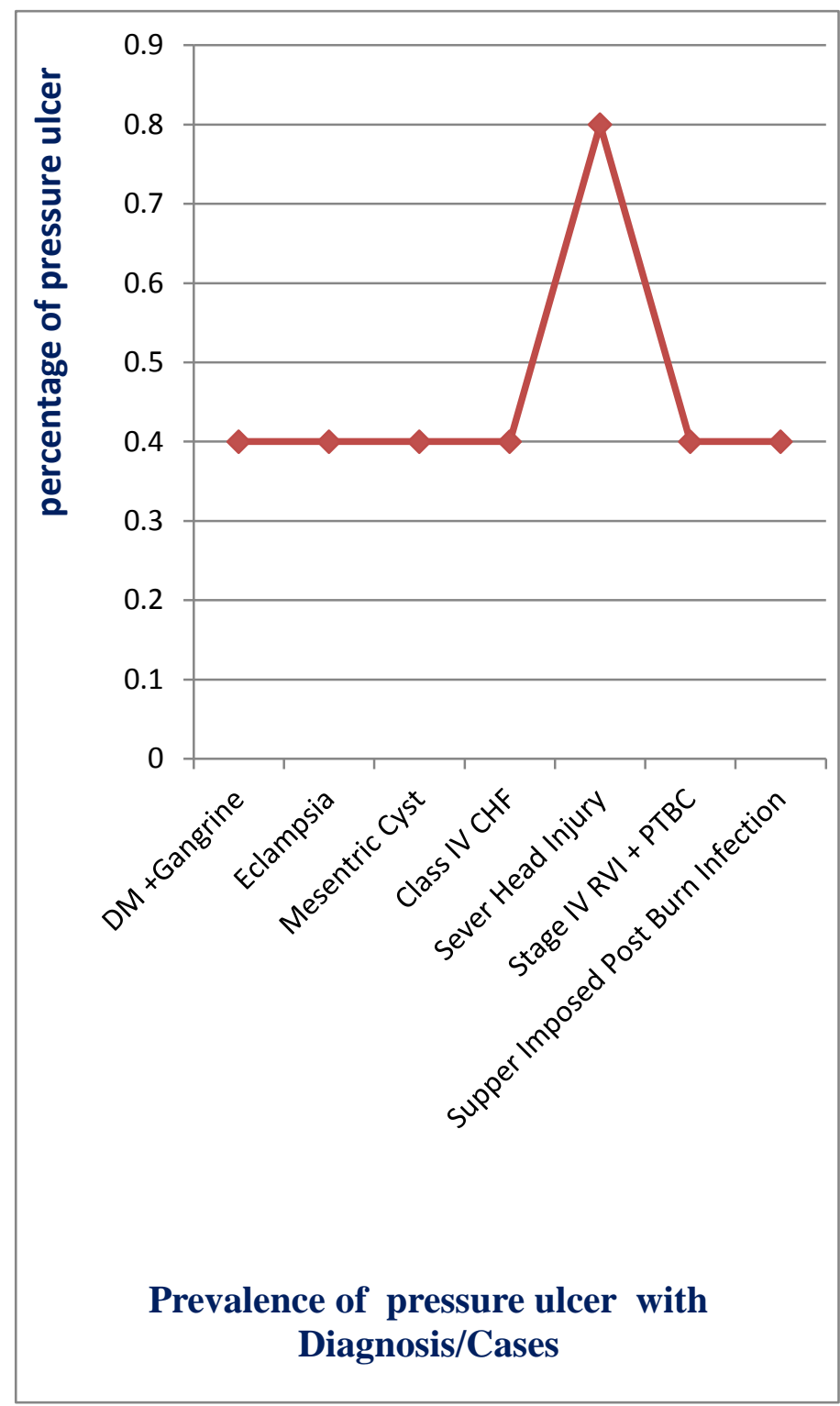

4.2.4. Prevalence of Pressure ulcer with Diagnosis/Cases

The prevalence of pressure ulcer based on the patients' cases were also identified, then from the total prevalence of pressure ulcer, the patients who had severe head injury comprised $0.8 \%(2)$, and the rest each accounted 0.4\%(1)(Fig.6).

Figure 5: Pressure Ulcer based on diagnosis of the respondents who were admitted at Debre Markos Referral Hospital, East Gojjam, Ethiopia, 2016 ( $n=236)$.

\subsubsection{Prevalence of pressure ulcer with Anatomical location}

Of those who developed pressure ulcer, most of the participants $2.50 \%$ (5) developed ulcer on sacral area and $0.40 \%$ (1) patients developed pressure ulcer at Occipital area (Fig-7). 


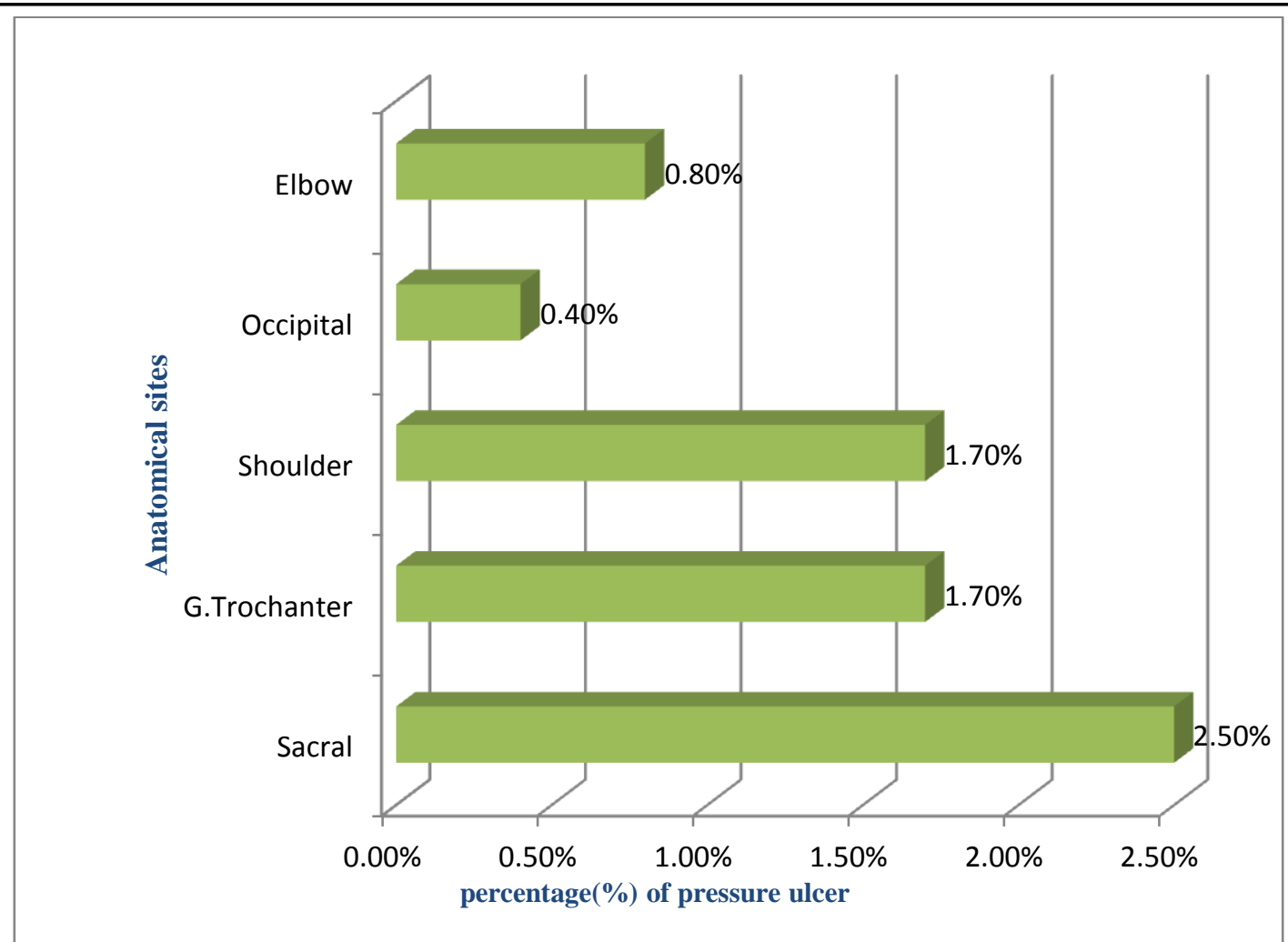

Figure 6: Anatomical location of pressure ulcer in patients who were admitted at Debre Markos Referral Hospital, East Gojjam, Ethiopia, 2016 ( $n=236)$.

4.2.6. Prevalence of pressure ulcer with EPUAP stages of ulcer

Among pressure ulcer developed participants, $0.4 \%$ (1) comprised the advanced stage (stage IV) of pressure ulcer (Fig.8).

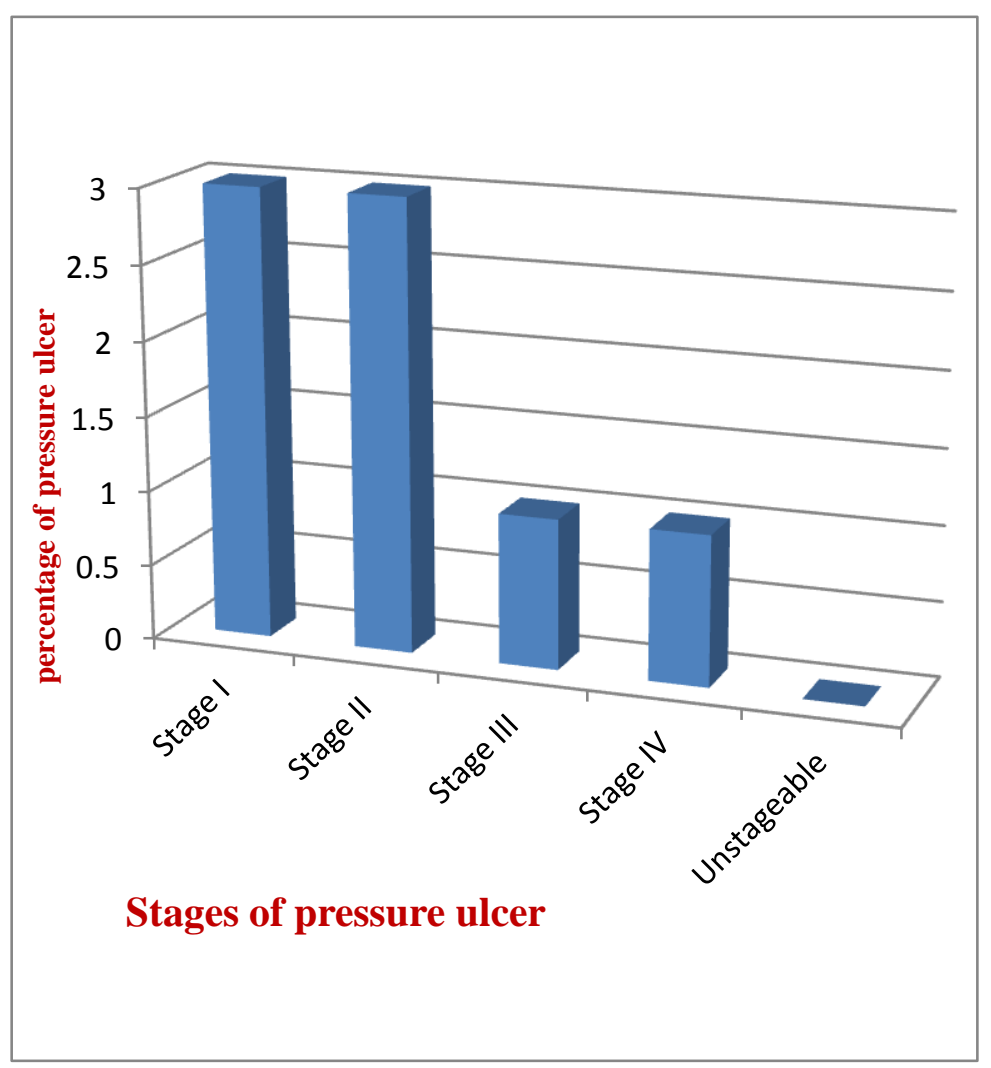

Figure 7 : Stages of pressure ulcer in patients who were admitted at Debre Markos Referral Hospital, East Gojjam, Ethiopia, 2016 ( $\mathrm{n}=236)$. 


\subsection{Braden Scale Pressure Ulcer Risk} Assessment

Majority of respondents $96.2 \%$ (227) had no impairment in sensory perception, and from the total respondents, $2.5 \%$ (6) were completely immobile. $11.9 \%$ ( 28) participants were probable inadequate in nutrition, and $5.1 \%$ (12) of the patients had potential problem in Friction \& Shear (Table-4).

Table 4: Braden Scale Pressure Ulcer Risk Assessment characteristics of the respondents who were admitted at Debre Markos Referral Hospital, East Gojjam, Ethiopia, 2016(N=236).

\begin{tabular}{|c|l|l|}
\hline Variables & Frequency & $\%$ \\
\hline Sensory perception & & \\
Completely limited & 2 & .8 \\
Very limited & 5 & 2.1 \\
Slightly limited & 2 & .8 \\
No impairment & 227 & 96.2 \\
\hline Constantly moist & & \\
Very moist & 2 & .8 \\
$\quad$ Occasionally moist & 5 & 2.1 \\
Rarely moist & 2 & .8 \\
Moisture & 227 & 96.2 \\
Activity $\quad$ & \\
Bed fast & 3 & \\
Chair fast & 7 & 1.3 \\
Walks occasionally & 5 & 2.0 \\
Walks frequently & 221 & 93.6 \\
\hline Completely immobile & 6 & \\
Very limited & 5 & 2.5 \\
Slightly limited & 6 & 2.1 \\
No limitation & 219 & 2.5 \\
\hline Mobility & 92.8 \\
\hline Very poor & 6 & \\
Probably inadequate & 28 & 2.5 \\
Adequate & 202 & 11.9 \\
Problem & 2 & 85.6 \\
\hline Potential problem & 12 & .8 \\
\hline No apparent problem & 222 & 5.1 \\
\hline Friction and shear & & 94.1 \\
\hline
\end{tabular}

\subsection{Factors of association with pressure ulcer}

\subsubsection{Socio-demographic and other variables}

Eleven independent variables were analyzed in logistic regression with outcome variable to know their association. Those variables which were significant at $\mathrm{P}<1.000$ entered into multivariate logistic regressions. This multivariate analysis had identified that patient's age, bedridden, and position change had significantly associated with pressure ulcer.
Those respondents whose age were in between 18 32 yrs had 0.45 times [95\% CI: AOR, 0.451[0.008 - 0.750] less likely to develop pressure ulcer than those who age were $\geq 54$ years. Patients who were bedridden had 13.8 times [95\% CI: AOR, 13.844 (11.480 - 31.101)] more possibly to develop pressure ulcer than those who were not bedridden, and those who had got position change service were 0.3 times [95\% CI: AOR, $0.30(0.000-$ 0.906)] less likely to develop pressure ulcer than who did not get the service (Table 5). 
Table 5: Factors of association variables with pressure ulcer of the respondents who were admitted at Debre Markos referral hospital, East Gojjam, Ethiopia, 2016 ( $n=236)$.

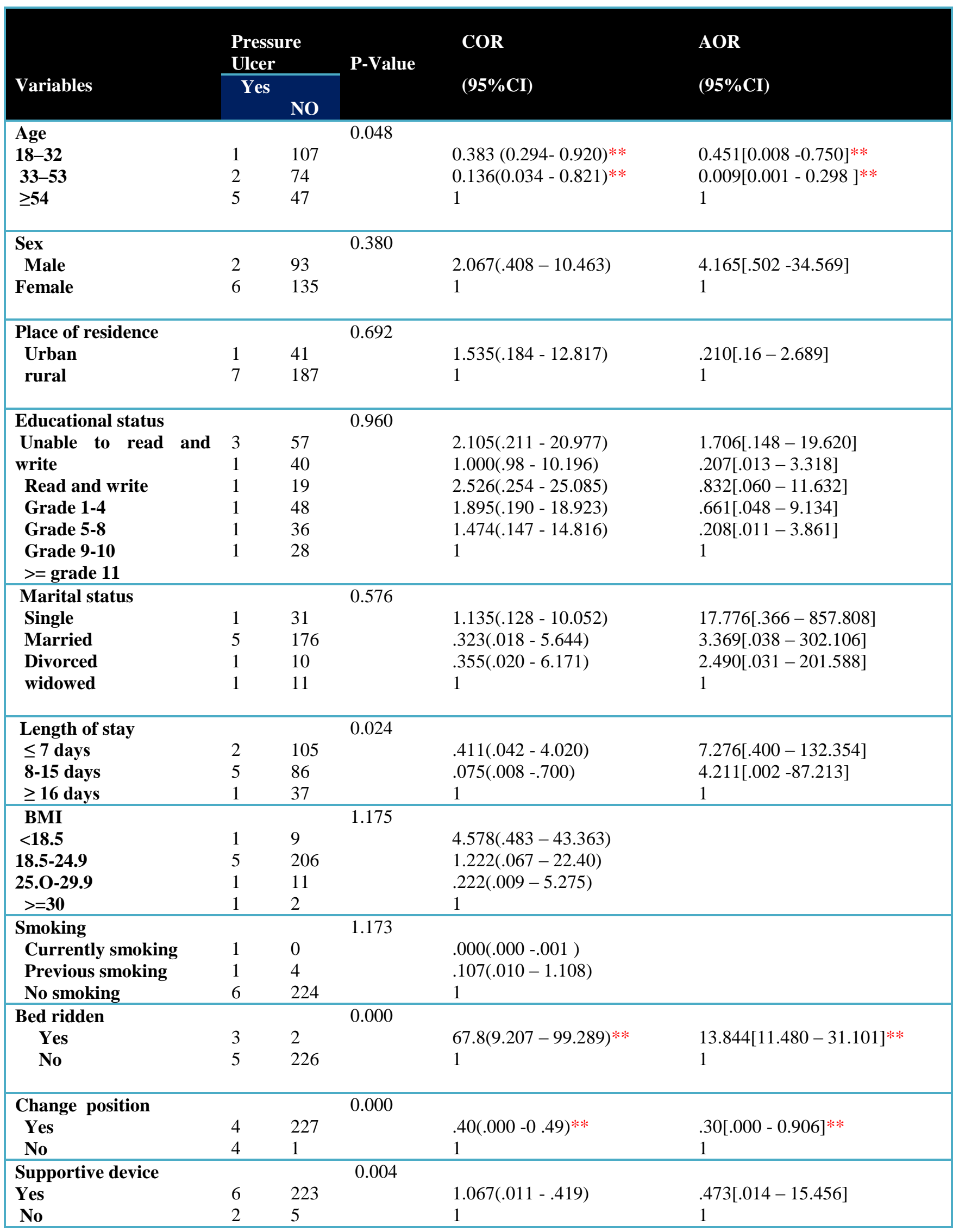

$\mathrm{NB}: *=\mathrm{p}<1.000, \quad * *=\mathrm{p} \leq 0.05$

Logistic Regression Method 'ENTER' Was Used For Multivariate Analysis. 


\subsubsection{Braden Scale Pressure Ulcer Risk Assessment}

Six predictors were analyzed in logistic regression with dependent variable of pressure ulcer to know their association, and those variables which were significant at $\mathrm{P}<1.000$ entered in to multivariate logistic regressions. Respondents who had constantly moist skin were 3.2 times $[95 \% \mathrm{CI}$ :
AOR, 3.202[2.050 -16.067] more risk to develop pressure ulcer than rarely moist skin in moisture. Those participants who had been very poor in nutrition were 4.9 times [95\% CI: AOR, 4.906(3.837 - 23.326)] at higher risk to develop pressure ulcer than adequate in nutrition (Table$6)$.

Table 6: Factors Associated With Braden Scale Pressure Ulcer Risk Assessment Variables And Pressure Ulcer of the Respondents Who Were Admitted At Debre Markos Referral Hospital, East Gojjam, Ethiopia, $2016(\mathrm{~N}=236)$.

\begin{tabular}{|c|c|c|c|c|c|}
\hline \multirow[t]{2}{*}{ Variables } & \multicolumn{2}{|c|}{$\begin{array}{l}\text { Pressure } \\
\text { Ulcer }\end{array}$} & \multirow[b]{2}{*}{$\begin{array}{l}\text { P- } \\
\text { Value }\end{array}$} & \multirow{2}{*}{$\begin{array}{l}\text { COR } \\
(95 \% \mathrm{CI})\end{array}$} & \multirow{2}{*}{$\begin{array}{l}\text { AOR } \\
(95 \% \mathrm{CI})\end{array}$} \\
\hline & Yes & NO & & & \\
\hline $\begin{array}{l}\text { Sensory perception } \\
\text { Completely limited } \\
\text { Very limited } \\
\text { Slightly limited } \\
\text { No impairment }\end{array}$ & $\begin{array}{l}1 \\
4 \\
1 \\
2\end{array}$ & $\begin{array}{l}0 \\
0 \\
1 \\
223\end{array}$ & 1.00 & $\begin{array}{l}.000[.000-.] \\
.000[.000-.] \\
.045[.003-.579] \\
1\end{array}$ & \\
\hline $\begin{array}{l}\text { Moisture } \\
\qquad \begin{array}{l}\text { Constantly moist } \\
\text { Very moist } \\
\text { Occasionally moist } \\
\text { Rarely moist }\end{array}\end{array}$ & $\begin{array}{l}2 \\
4 \\
1 \\
1\end{array}$ & $\begin{array}{l}0 \\
1 \\
1 \\
226\end{array}$ & .000 & $\begin{array}{l}8.005[2.090-78.074]^{* *} \\
4.008[1.001-45.082]^{* *} \\
2.009[1.000-39.205]^{* *} \\
1\end{array}$ & $\begin{array}{l}3.202[2.050-16.067]^{* *} \\
3.060[1.000-17.081]^{* *} \\
2.021\left[1.001-22.740^{* *}\right. \\
1\end{array}$ \\
\hline $\begin{array}{l}\text { Activity } \\
\text { Bed fast } \\
\text { Chair fast } \\
\text { Walks occasionally } \\
\text { Walks frequently }\end{array}$ & $\begin{array}{l}2 \\
4 \\
1 \\
1\end{array}$ & $\begin{array}{l}0 \\
4 \\
3 \\
221\end{array}$ & 1.000 & $\begin{array}{l}.000[.000-.] \\
.000[.000-.] \\
.000[.000-.] \\
1\end{array}$ & \\
\hline $\begin{array}{l}\text { Mobility } \\
\text { Completely immobile } \\
\text { Very limited } \\
\text { Slightly limited } \\
\text { No limitation }\end{array}$ & $\begin{array}{l}6 \\
1 \\
1 \\
0\end{array}$ & $\begin{array}{l}0 \\
4 \\
5 \\
219\end{array}$ & 1.053 & $\begin{array}{l}.000[.000-.] \\
.023[.001-.429] \\
.042[.002-.728] \\
1\end{array}$ & \\
\hline $\begin{array}{l}\text { Nutrition } \\
\qquad \begin{array}{l}\text { Very poor } \\
\text { Probably inadequate } \\
\text { Adequate }\end{array}\end{array}$ & $\begin{array}{l}5 \\
2 \\
1\end{array}$ & $\begin{array}{l}4 \\
23 \\
201\end{array}$ & .000 & $\begin{array}{l}8.125[2.592-56.721]^{* *} \\
4.750[2.917-44.614]^{* *} \\
1\end{array}$ & $\begin{array}{l}4.906[3.837-23.326]^{* *} \\
2.161[1.506-16.270]^{* *} \\
1\end{array}$ \\
\hline $\begin{array}{l}\text { Friction and shear } \\
\qquad \begin{array}{l}\text { Problem } \\
\text { Potential problem } \\
\text { No apparent problem }\end{array}\end{array}$ & $\begin{array}{l}1 \\
4 \\
3\end{array}$ & $\begin{array}{l}1 \\
8 \\
219\end{array}$ & .000 & $\begin{array}{l}.357[.033-3.916] \\
10.048[.925-109.125] \\
1\end{array}$ & $\begin{array}{l}.495[.029-8.341] \\
.433[.017-11.110] \\
1\end{array}$ \\
\hline
\end{tabular}

NB: $* \mathrm{p}<1.000, * *=\mathrm{p} \leq 0.05$

Logistic Regression Method 'ENTER' Was Used For Multivariate Analysis. 


\section{Discussion}

\subsection{Prevalence of pressure ulcer}

\subsubsection{Overall prevalence of pressure ulcer}

In this study, the overall prevalence of pressure ulcer was $3.4 \%$. This result was slightly higher than studies conducted in China and Nigeria with prevalence of $1.58 \%, 3.22 \%$ respectively ${ }^{(3,9)}$. Higher prevalence in this study might be due to inappropriate nursing care, inadequate \& very poor feeding habit and limited resource of pressure relieving devices.

It was also found that the prevalence rate was lower than a study conducted in Brazil 16.9\%, Germany $26.5 \%$,Sweden 22.9\%,Canada (Ontario) 25.7\%, and Felege Hiwot hospital (Bahir Dar) $16.8 \%{ }^{(12,17,18,9,7)}$. This discrepancy might be due to different characteristics of participants, disease condition of patients and also the variation of study period \&length of stay in hospital.

5.1.2. Prevalence of pressure ulcer with anatomical location.

In this study, prevalence of pressure ulcer due to anatomical location was lower (Sacral, G. Trochanter \& Elbow $2.5 \%, 1.7 \% \quad \& 0.8 \%$ respectively) than a study conducted in China (Sacral, G.Trochanter \& Elbow 60.52\%,6.34\% $\& 0.79 \%$ ),in Brazil(Sacral, G.Trochanter \& Elbow $82.5 \%, 37.5 \%$ \&3.7\%) in Bahir Dar(Sacral, \& Elbow $70.4 \%, \& 7 \%$ ). This difference might be due to the disease condition of patients and variation of study area \&length of stay in hospital.

\subsubsection{Prevalence of pressure ulcer with stage}

In this study, prevalence of pressure ulcer in stages I, II \& IV were $2.5 \%, 2.5 \%$ \& $0.4 \%$ respectively. This finding was lower than a study conducted in China $28.68 \%, 35.82 \%, 12.99 \%$, in Brazil 30.3\%,32.4\% 13.9\%, in Ahmadu Bello University (Nigeria), and in Bahir Dar (Felege Hiwot hospital) $62 \%, 26.8 \%, 2.8 \%(3,12,20,7)$. This discrepancy might be due to different characteristics of participants, disease condition of patients and sample size the participants.
5.2. Association of variables with pressure ulcer

\subsubsection{Association of demographic variables with pressure ulcer.}

This study depicted that pressure ulcer was significantly associated $(\mathrm{p}<0.048)$ with age ,it was in line with a study conducted by Bergstron \&Braden ${ }^{(25)}$; but not supported by a survey conducted in the city of Belo Horizonte (Brazil), China, Nigeria and Bahir Dar (Felege Hiwot hospital $)^{(25,3,9,7)}$. The reason not in lined to other studies might be the disease condition of patients and length of stay in hospital.

\subsubsection{Association of other variables with pressure ulcer}

Bed ridden and change in position were strongly associated $(\mathrm{p}=0.000)$ with the presence of pressure ulcer as shown in this study. Bed ridden association with pressure ulcer was in line with a study conducted in Brazil ${ }^{(12)}$, and change in position was also in line with a survey did in Bahir Dar,Felege Hiwot hospital ${ }^{(7)}$.

\subsection{Association of Braden RAS variables with pressure ulcer}

The Braden RAS tool with development of pressure ulcer in this study was identified; moisture and nutrition were the major predictors for pressure ulcer development, due to the fact that constantly moist skin and very poor in nutrition predispose patients to develop pressure ulcer.

The findings indicated that moist skin and very poor in nutrition were strongly \& significantly associated $(\mathrm{p}=0.000)$ with presence of pressure ulcer. These results were consistent with previous studies or in agreement with different studies conducted across 26 hospitals in Belgium, Italy, Portugal, Sweden \& UK(18), Brazil ${ }^{(12)}$, and a survey that was done by Richard A. Benoit, Jr. ${ }^{(21)}$, but not supported by a study conducted in Bahir Dar, Felege Hiwot hospital ${ }^{(7)}$. The possible explanation that was not supported by Felege Hiwot hospital might be the disease condition, and different characteristics of participants. 


\section{Conclusion}

The prevalence of pressure ulcer was slightly high among hospitalized adult patients. In this study, age, bedridden, position change, moisture and nutrition were significantly associated with the presence of pressure ulcer. So, Patients were more liable to develop pressure ulcer when they were in bed ridden, moist skin \& inadequate nutrition and had not been changed their position frequently.

\section{Appendix}

Braden scale pressure ulcer risk assessment

Sensory perception: sensory perception measures the individual ability to feel and report discomfort.

Completely limited: unresponsive (does not moan, flinch or grasp) to painful stimuli, due to diminished level of consciousness or sedation or limited ability to feel pain over most of the body.

Very limited: responds only to painful stimuli. Cannot communicate discomfort except by moaning or restlessness or has a sensory impairment which limits the ability to feel pain or discomfort over $1 / 2$ of body.

Slightly limited: respond to verbal commands, but cannot always communicate discomfort or the need to be turned or has some sensory impairment which limits ability to feel pain or discomfort in one or two extremities.

No impairment: responds to verbal commands. Has no sensory deficit which would limit ability to feel or voice pain or discomfort.

Moisture: moisture measures the degree to which the skin is exposed to moisture.

Constantly moist: skin is kept moist almost constantly by perspiration, urine, etc. dampness is detected every time patient is moved or turned.

Very moist: skin is often, but not always moist. Linen must be changed at least once a shift.

Occasionally moist: skin is occasionally moist, requiring an extra linen change approximately once a day.

Rarely moist: skin is usually dry; linen only requires changing at routine intervals.

Activity: degree of physical activity.

Bed fast: confined to bed.
Chair fast: ability to walk severely limited or non-existent. Cannot bear own weight and /or must be assisted in to chair or wheelchair.

Walks occasionally: walks occasionally during day, but for very short distances, with or without assistance. Spends majority of each shift in bed or chair.

Walks frequently: walks outside room at least twice a day and inside room at least once every 2hours during waking hours.

Mobility: ability to change and control body position.

Completely immobile: does not make even slight changes in body or extremity position without assistance.

Very limited: makes occasional slight changes in body or extremity position but unable to make frequent or significant changes independently.

Slightly limited: makes frequent through slight changes in body or extremity position independently.

No limitation: makes major and frequent changes in position without assistance.

Nutrition: nutrition reflects the food intake pattern of the assessed person, as well as liquid supplements.

Very poor: never eats a complete meal. Rarely eats more than $1 / 3$ of any food offered. Eats 2 servings or less of protein (meat or dairy products) per day. Takes fluid poorly. Does not take a liquid dietary supplement or is NPO and / or maintained on clear liquids or IVs for more than 5 days.

Probably inadequate: rarely eats a complete meal and generally eats only about $1 / 2$ of any food offered. Protein intake includes only 3 servings of meat or dairy products of per day. Occasionally will take a dietary supplement or receives less than optimum amount of liquid diet or tube feeding.

Adequate: eats over half of most feels. Eats a total of 4 servings of protein (meat, dairy products) per day. Occasionally will refuse a meal, but will usually take a supplement when offered or is on a tube feeding. 
Friction /shear: friction and shear assess the person's ability to keep the skin free from contact with the wrinkle area.

Problem: requires moderate to maximum assistance in moving. Complete lifting without sliding against sheets is impossible. Frequently slides down in bed or chair, requiring frequent repositioning with maximum assistance. Spasticity, contractures or agitation leads to almost constant friction.

Potential problem: moves feebly or requires minimum assistance. During a move skin probably slides to some extent against sheets, chair, restraints or other devices. Maintains relatively good position in chair or bed most of time but occasionally slides down.

No apparent problem: moves in bed and in chair independently and has sufficient muscle strength to lift up completely during move. Maintains good position in bed or chair.

\section{Acknowledgment}

Firstly, I would like to thank my almighty God for keeping me healthy alive, reach to do this work and ahead in time to the future.

Secondly, I would like to thank to Addis Ababa University, College of Health Sciences, School of Allied Health Science, Department of Nursing and Midwifery for financial support.

Finally, my in-depth gratitude goes to address my sincerest and heartfelt appreciation to my advisors Ato Balcha Berhanu (MSc, BSc, RN), Ato Dessalegn Haile(MSc, BSc, RN) \&Ato Bekele Tesfaye (MSc, BSc, RN) for their concrete \& unreserved guidance, constructive suggestions and comments in each step of the thesis.

\section{References}

1. Bm G, Wp C, Mcinnes E, Kent B, Ja W. Repositioning for pressure ulcer prevention in adults ( Protocol ). 2012;(7).

2. Qaseem A, Mir TP, Starkey M, Denberg TD. Risk Assessment and Prevention of Pressure Ulcers: A Clinical Practice
Guideline From the American College of Physicians. 2015;(July 2014):359-70.

3. Jiang Q, Li X, Qu X, Liu Y, Zhang L, Su $\mathrm{C}$, et al. The incidence, risk factors and characteristics of pressure ulcers in hospitalized patients in China. 2014;7(5):2587-94.

4. Ulcer P, Assessment R. Effective Health Care Program. Agency Healthc Reseach Qual Excell Heal care. 2006;(87).

5. Gedamu H, Hailu M, Amano A. Prevalence and Associated Factors of Pressure Ulcer among Hospitalized Patients at Felegehiwot Referral Hospital , Bahir Dar, Ethiopia. 2014;2014.

6. Vangilder C, Vangilder C, Amlung S, Harrison P, Meyer S. Results of the 20082009 International Pressure Ulcer Prevalence Survey and a 3- year, acute care, unitspecific analysis. 2009; (NOVEMBER).

7. Boa A, Ac O, Lo A, Ao A. Pressure ulcer prevalence among hospitalised adults in university hospitals in South-west Nigeria. wound Pract Pesearch. 2013;21:128-34.

8. Cox BJ. P u a c c p,P REDICTORS OF PRESSURE ULCERS IN ADULT CRITICAL CARE PATIENTS. Am Assoc Crit Nurses. 2011;20(5):364-75.

9. Kuffler DP. Techniques for Wound Healing with a Focus on Pressure Ulcers Elimination. 2010;72-84.

10. Brito A, Sc M, Vasconcelos S De, Ph G, Isabel M, Davisson T, et al. Prevalence of pressure ulcers in hospitals in Brazil and association with nutritional status d A multicenter, cross-sectional study Patr. 2013;29:646-9.

11. Dorner AB, Posthauer ME, Thomas D. The Role of Nutrition in Pressure Ulcer Prevention and Treatment. Natl Press Ulcer Advis Panel. 2009;(3):1-15.

12. Prentice JL SM. Pressure ulcers : the case for improving prevention and management in Australian health care settings. Prim Intent. 2001;9(3):111-20. 
13. Pacific PAN. Prevention and Treatment of Pressure Ulcers : Quick Reference Guide. 2014. 75 p.

14. Jl P, Mc S, Lewin G, J1 P, Mc S, Jl P, et al. An Australian model for conducting pressure ulcer prevalence surveys. 2003;11(2).

15. Heidi Heinhold, Andreas Westerfellhaus KK. Prevalence of Pressure Ulcers in Hospitalized Patients in Germany,Trends from 2005 to 2011. EWMA. 2014;14(1):9-14.

16. Occur U, Ulcers P. Why do Pressure Pressure Ulcer Formation: Ulcers Occur? Patients Populations at Pathophysiology of Highest Risk Pressure Ulcers Pressure Ulcer Formation: Patient Populations at Highest Risk. 2013;

17. Houghton PE. P REVALENCE OF $P$ RESSURE U LCERS IN C ANADIAN HEALTHCARE SETTINGS. O s to my / Wound Ma n a gem en. 2004;50(10):2238.

18. Awwal LM, Khalid S, Hadiza M, Farouk MA. Pressure Ulcer Stages among BedRidden Patients in Ahmadu Bello University Teaching Hospital ( ABUTH ), Zaria- Nigeria. 2014;3(1):61-8.

19. Rosa J, Blanes L, Calil JA, Maria J, Chacon F, Ferreira LM. Prevalence of pressure ulcers in a brazilian hospital:results of a cross sectional study. ostomy wound Manag. 2010;56(10):52-7.

20. Lahmann NA, Tannen A, Kuntz S, Raeder $\mathrm{K}$, Schmitz G, Dassen T, et al. International Journal of Nursing Studies Mobility is the key! Trends and associations of common care problems in German longterm care facilities from 2008 to 2012. Int J Nurs Stud [Internet]. Elsevier Ltd; 2015;52(1):167-74. Available from: http://dx.doi.org/10.1016/j.ijnurstu.2014.07.014
21. Richard A. Benoit J. RISK FACTORS FOR PRESSURE ULCER DEVELOPMENT IN CRITICAL ILL PATIENTS. 2013;195.

22. Petzold T, Carl U, Carus G, Eberleingonska $\mathrm{M}$. Which factors predict incident pressure ulcers in hospitalized patients? Br J Dermatol. 2014; (October 2015).

23. Lyder CH, Ayello EA. Chapter 12. Pressure Ulcers: A Patient Safety Issue. 2005;

24. Care W. Evidence-Based Prevention of Pressure Ulcers. 2013;33(6):57-67.

25. Associados F, Por ÀÚ, Em P, Internados P, Temponi HR, Velásquez-meléndez G. Factors associated to pressure ulcers in patients at Adult Intensive Care Units. 2010;44(4):1065-71.

26. Central statistical agency. summary and stastical report of 2007 population and housing census. addis ababa; 2007.

27. How BB, Service PH. Braden Scale for Predicting Pressure Sore Risk. 2004;1992(3).

28. Ayello EA. Predicting Pressure Ulcer Risk Excelsior College School of Nursing. try this Gen Assess Ser. 2012;55(5). 